Medicine, Dentistry and Veterinary Medicine is hosting the Second Inter-

\title{
The use of elearning in medical education
}

\section{Kay Mohanna}

The advent of elearning has provided a valuable tool for the teaching of medical education

$\mathrm{H}$ wany times today have you "Googled" for a quick answer to a query? The information explosion means that we all have rapid access to material that in the past needed the help of a friendly medical librarian and a week off work to browse. We are used to this supporting our clinical work so it is not surprising that we are increasingly turning to it to support our teaching and learning.

As Tony Choules, consultant paediatrician, points out in this issue, computers are good at storing information. ${ }^{1}$ The clever bit is how we as teachers can selectively use it in teaching and guide our learners to discriminate and make the best use of it. This article reminds us that we still need the traditional skills to align our teaching strategy with our teaching and learning objectives, but elearningprovision of instructional resources, activities, assessments and feedback onlineis a valuable addition to the teaching tool box.

Blended learning is the "next big thing" in medical education. The Higher Education Academy Subject Centre for national Blended Learning Conference this summer (http://www.medev.ac.uk). Blended learning is an approach that combines traditional and electronic media to cater for the "net generation learner". This might include curriculum design, computer supported collaborative learning, computer aided assessment, learning materials and learning objects, content management systems, change management strategies, institutional policies, and patient education and involvement.

(See page 212)

Postgrad Med J 2007;83:211.

doi: $10.1136 /$ pgmi.2007.058610

Correspondence to: Dr Kay Mohanna, Staffordshire University, Faculty of Health and Science, Blackhealth Lane, Stafford, Staffordshire, ST15 OAD, UK; kaymohanna@aol.com

Conflict of interest: none stated

\section{REFERENCE}

1 Choules AP. The use of elearning in medica education: a review of the current situation. Postgrad Med J 83:XX-XX

Techniques and applications of molecular biology: a course for medical practitioners

16 - 19 July 2007

A four-day residential course for those in the medical profession wishing to improve their understanding of the principles and applications of genetic engineering techniques.

Details: Dr Charlotte Moonan, Department of Biological Sciences, University of Warwick, Coventry, CV4 7AL; tel: +44 (0) 247652 3540; email Charlotte.Moonan@warwick.ac.uk; website www.warwick.ac.uk/go/bioscienceshortcourses. 